\title{
Formas contemporâneas de fazer pesquisa em História da Psicologia
}

\section{Contemporary research methods in the History of Psychology}

Formas contemporáneas de hacer investigación en Historia de la Psicología

\section{Kely Cristina Garcia Vilena*}

Universidade Católica Dom Bosco - UCDB, Campo Grande, Mato Grosso do Sul, Brasil

\section{Marciana Vieira de Souza Xavier**}

Universidade Católica Dom Bosco - UCDB, Campo Grande, Mato Grosso do Sul, Brasil

\section{Rodrigo Lopes Miranda***}

Universidade Católica Dom Bosco - UCDB, Campo Grande, Mato Grosso do Sul, Brasil

Assis, R. M. \& Peres, S. P. (Orgs.). (2016). História da Psicologia: Tendências Contemporâneas. Belo Horizonte: Ed. Artesã.

O livro História da Psicologia: Tendências Contemporâneas, obra organizada por Raquel Martins de Assis e Sávio Passafaro Peres é fruto do trabalho desenvolvido pelo Grupo de Trabalho em História da Psicologia da Associação Nacional de Pesquisa e Pós-Graduação em Psicologia (ANPEPP) e reúne questões e temas atuais no campo da historiografia. Ele contém dez capítulos e está dividido em três seções, a saber: 1) Historiografia da Psicologia; 2) Fontes e Arquivos em História da Psicologia; 3) Psicologia, Cultura e Circulação de Saberes. Os capítulos abordam temas urgentes em historiografia da psicologia e foram escritos por pesquisadores vinculados a diferentes instituições no Brasil o que permite ao leitor uma multiplicidade de visões da historiografia e das histórias da Psicologia.

A primeira seção, Historiografia da Psicologia, convida o leitor a uma reflexão sobre a forma de se fazer historiografia. Ao final de cada capítulo, nota-se que a intenção dos autores foi chamar a atenção quanto à necessidade do uso de diferentes instrumentos para pesquisas rigorosas em História da Psicologia e a importância de aproximação com a História da Ciência, História da Filosofia, História 
Cultural, dentre outros campos. São apresentadas, também, profícuas reflexões e discussões teórico-metodológicas na produção das Psicologias, em um contexto global-local, tais como uma tendência contemporânea de pesquisa. Evidencia-se isso no terceiro capítulo: A biografia na historiografia da psicologia: questões teóricas e metodológicas preliminares, em que se discute a biografia como um gênero para a historiografia da Psicologia (Cruz, 2016). Cruz (2016) destaca como a biografia se tornou um dos mais populares dos gêneros literários ao final do século XX, além de discutir as transformações e debates sobre a escrita biográfica na historiografia das ciências e seus impactos na historiografia da Psicologia. Neste sentido, revela críticas às tradicionais biografias e a emergência de duas novas tendências. Uma composta pela escrita da história de vida de psicólogos e psicólogas, até então excluídos da história da Psicologia e outra, configurada na reescrita biográfica dos chamados grandes personagens da ciência. Esse modelo de historiografia tem contribuído na compreensão de traços humanos em meio aos acontecimentos do passado. Além disso, elas concorrem para um entendimento de parcelas da cultura e da sociedade com as quais o autor biografado se relacionava e contribuía na constituição.

A seção Fontes e Arquivos em História da Psicologia é a segunda apresentada pela obra e discute sobre fontes e arquivos em História da Psicologia como elementos essenciais para as pesquisas historiográficas. O primeiro capítulo, por exemplo, conta como foram constituídos os Arquivos da Universidade Federal de Minas Gerais (UFMG) de História da Psicologia no Brasil que reúnem hoje um conjunto de documentos relacionados à história da psicologia, das ciências e da educação no país (Campos \& Lourenço, 2016). As autoras iniciam o texto apresentando como foi o processo de organização e preservação de tais documentos, com ênfase na revitalização do acervo de Helena Antipoff. Além disso, introduzem como se constituiu o Grupo de Trabalho (GT) em História da Psicologia da Associação Nacional de Pesquisa e Pós-Graduação em Psicologia (ANPEPP) e as contribuições do psicólogo-historiador Josef Brožek para aos Arquivos UFMG. A discussão sobre a constituição de arquivos em História da Psicologia tem se tornado frequente, no país. Nota-se, por exemplo, a constituição de arquivos que estabelecem a memória de figuras importantes na história do campo Psi no Brasil, tais como Luís Marcellino de Oliveira, Miguel Covian e Reinier Rozestraten (Damasceno \& Massimi, 2013; Marcelo, Franca, Rohden, Soares Junior, \& Miranda, 2016; Péron, Nogueira, Cândido, \& Massimi, 2016). Desse modo, percebe-se o interesse de diversos pesquisadores por arquivos pessoais e fontes primárias, reforçando outro ponto positivo da obra: a contribuição dos arquivos para possíveis interessados em historiografia da psicologia. 
Por fim, a terceira seção, Psicologia, Cultura e Circulação de Saberes, apresenta em três capítulos, como os discursos psicológicos estão presentes nos mais variados contextos de formação da cultura brasileira em diferentes épocas. Isso é retratado, por exemplo, no capítulo em que se analisa a obra de Machado de Assis, como modelo de apropriação de concepções e teorias psicológicas (Peres, 2016). Para o autor do capítulo, o uso da obra literária exemplifica como conceitos sociais ou psicológicos podem facilitar o entendimento de aspectos importantes da literatura que para o leitor comum passaria sem qualquer relevância. Além disso, o autor pontua como os processos de apropriação e de circulação de conhecimento perpassam diferentes culturas, práticas, ideias e sujeitos. Destaca, ainda, como uma obra literária pode se tornar uma rica fonte de divulgação da Psicologia. Percebe-se que a obra literária, juntamente com outros meios de circulação de conhecimento, vem compor não só fontes importantes de divulgação da Psicologia, mas se torna essencial a prática da História da Psicologia.

Um ponto positivo da obra é a forma de exposição de tais "tendências contemporâneas" com a apresentação de objetos e métodos de modo simples, mas criterioso. Além disso, nos capítulos objetivou-se, o máximo possível, situar suas perspectivas com investigações internacionais, permitindo uma visão global-local de abordagens teórico-metodológicas da História do campo Psi, o que tem como consequência favorecer um conhecimento aprofundado aos leitores interessados. A leitura dessa obra, assim, indica que a história da Psicologia não está apenas presente em textos acadêmicos, mas em diversas abordagens, instituições, práticas psicológicas, aspectos socioculturais, dentre outros. Fica, portanto, um convite à leitura do material, bem como, à produção de rigorosas histórias da Psicologia.

\section{Referências}

Campos, R. H. F. \& Lourenço, E. (2016). Os Arquivos UFMG de História da Psicologia no Brasil: fontes primárias para a pesquisa historiográfica. In R. M. Assis \& S. P. Peres (Orgs.), História da Psicologia: Tendências Contemporâneas (pp. 91120). Belo Horizonte: Ed. Artesã.

Cruz, R. N. (2016). A biografia na historiografia da Psicologia: questões teóricas e metodológicas na escrita da vida científica. In R. M. Assis \& S. P. Peres (Orgs.), História da Psicologia: Tendências Contemporâneas (pp. 51-69). Belo Horizonte: Ed. Artesã.

Damasceno, E. \& Massimi, M. (2013). Diálogos epistolares como fontes para a História das Ciências: A correspondência de Miguel Rolando Covian. Diálogos Possíveis, 12(2), 78-79. 
Recuperado

de http:// www.faculdadesocial.edu. br/revistas/index.php/dialogosp ossiveis/article/view/63

Marcelo, A. C., Franca, J. S., Rohden, R. F. S., Soares Junior, R. C. \& Miranda, R. L. (2016). Reinier Rozestraten's Archives of the History of Psychology. History of Psychology, 19(3), 256-257.

Peres, S. P. (2016). A literatura como fonte para a história da psicologia: o caso Machado de Assis. In R. M. Assis \& S. P. Peres (Orgs.), História da Psicologia: Tendências Contemporâneas (pp. 191-205). Belo Horizonte: Ed. Artesã.

Péron, S., Nogueira, E., Cândido, G. V. \& Massimi, M. (2015). Luiz Marcellino de Oliveira: um protagonista da psicologia brasileira: organização de acervo documental e análise histórica. Memorandum, 29, 86-111. Recuperado de http://www.fafich.ufmg.br/memorandum/a29/peronnogueiraca ndidomassimi01/

\section{Endereço para correspondência \\ Kely Cristina Garcia Vilena}

Universidade Católica Dom Bosco - UCDB

Av. Tamandaré, 6000, Jardim Seminário, CEP 79117-900, Campo Grande - MS, Brasil

Endereço eletrônico: kelyvilhena@yahoo.com.br

\section{Marciana Vieira de Souza Xavier}

Universidade Católica Dom Bosco - UCDB

Av. Tamandaré, 6000, Jardim Seminário, CEP 79117-900, Campo Grande - MS, Brasil

Endereço eletrônico: marcianaxavier@gmail.com

Rodrigo Lopes Miranda

Universidade Católica Dom Bosco - UCDB

Av. Tamandaré, 6000, Jardim Seminário, CEP 79117-900, Campo Grande - MS, Brasil

Endereço eletrônico: rlmiranda@ucdb.br

Recebido em: $31 / 10 / 2018$

Aceito em: 12/01/2019

\section{Notas}

* Mestre em psicologia pela UCDB e Doutoranda em Psicologia pelo mesmo programa. Docente no curso de graduação em Enfermagem da UCDB.

** Mestranda em psicologia pela Universidade Católica Dom Bosco - UCDB. Graduação em psicologia pela Universidade Federal do Rio de J aneiro - UFRJ .

*** Doutor em educação pela Universidade Federal de Minas Gerais - UFMG. Docente e pesquisador no Programa de Pós-Graduação Mestrado e Doutorado em Psicologia da Universidade Católica Dom Bosco.

Este artigo de revista Estudos e Pesquisas em Psicologia é licenciado sob uma Licença Creative Commons Atribuição-Não Comercial 3.0 Não Adaptada. 